\title{
Taş Hastalarının Çağdaş Radyolojik Yöntemlerle Değerlendirilmesi ve Ufuktaki Yeni Görüntüleme Yöntemleri
}

\author{
Tamer Baysal ${ }^{1}$
}

${ }^{1}$ Kartal Dr. Lütfi Kırdar Eğitim ve Araştirma Hastanesi, Radyoloji Kliniği, Istanbul

\section{Giriş}

$\bigcup^{\bullet}$ riner sistem taş hastalığının tanısında kullanılan konvansiyonel görüntüleme yöntemleri arasında direkt üriner sistem grafisi (DÜS), intravenöz piyelografi (IVP), ultrasonografi (US) ve kontrastsız bilgisayarlı tomografi (BT) bulunmaktadır. Son yıllarda ise multidedektör BT (MDBT), düşük doz BT ve dual enerji BT (DEBT) yöntemleri öne çımiştır.

\section{Görüntüleme Tekniklerinin Dezavantajları}

\section{DÜS}

DÜS grafi barsak gazlarının fazla olduğu durumlarda, böbrek dışı kalsifikasyonları ayırt etmede ve obez hastalarda tanıda yetersiz kalmaktadır. Günümüzde DÜS grafinin kullanıldığı yerler floroskopi eşliğinde ESWL, ESWL sonrası parçalanan taşların takibinde, üreteroskopi ve perkütan nefrolitotomi işlemidir (1).

\section{IVP}

$\mathrm{Bu}$ radyolojik görüntüleme yönteminde \%31-48 gibi yüksek oranda taş atlandığ dezavantajları intravenöz yoldan iyotlu kontrast madde kullanımidir (1).

\section{US}

İyonizan radyasyon içermeyen bir görüntüleme yöntemidir. Önemli bir dezavantajı "yapana bağımlı" olmasıdır. US işlemi yapan kişinin tecrübesi büyük önem taşımaktadır. En tecrübeli eller bile distal üreter taşını gösteremeyebilir. US taş hastalığının tespitinde sınırlı tanısal değere sahip olup, radyasyon içermemesi nedeniyle çocuk ve gebelerde tercih edilmelidir $(1,2)$.

\section{Bilgisayarlı Tomografi}

\section{Kontrastsız BT}

1990'larda kullanıma girmesi ile pek çok merkezde IVP ve DÜS grafinin yerini almıştır. 1998'de multidedektör BT teknolojisinin kullanıma girmesiyle taş tespitinde çok önemli değişiklikler olmuştur $(3,4,5)$. BT'nin taş tespitinde en önemli dezavantajlarından birisi "parsiyel volüm" etkisidir. Kesit kalınlığı arttıkça kesit kalınlığından daha küçük boyutta olan taş voksel içerisinde tam olarak temsil edilemeyebilir (Şekil 1). İnce kesit kalınlığı ise hastanın maruz kalacağı radyasyon dozunun artmasına neden olur. Bu nedenle taş tespitinde kesit kalınlığı ve aralığının optimum değerleri önceden belirlenmelidir. Az sayıda merkezde kullanılan "dual enerji $\mathrm{BT}^{\prime \prime}$ taş analizinde sağladığ yöntemlere belirgin üstünlük sağlamıştır.

\section{Düşük doz BT}

Taş hastalığı nedeniyle takip edilen hastalarda tekrarlanan tetkikler nedeniyle kümulatif radyasyon dozu yüksektir. Tetkike böbrekler, üreterler ve mesane dâhil edilmelidir. Üç mm yerine $5 \mathrm{~mm}$ alınan kesitlerde radyasyon dozu \%30-50 oranında azalmaktadır (Şekil 2). Çok düşük doz uygulaması
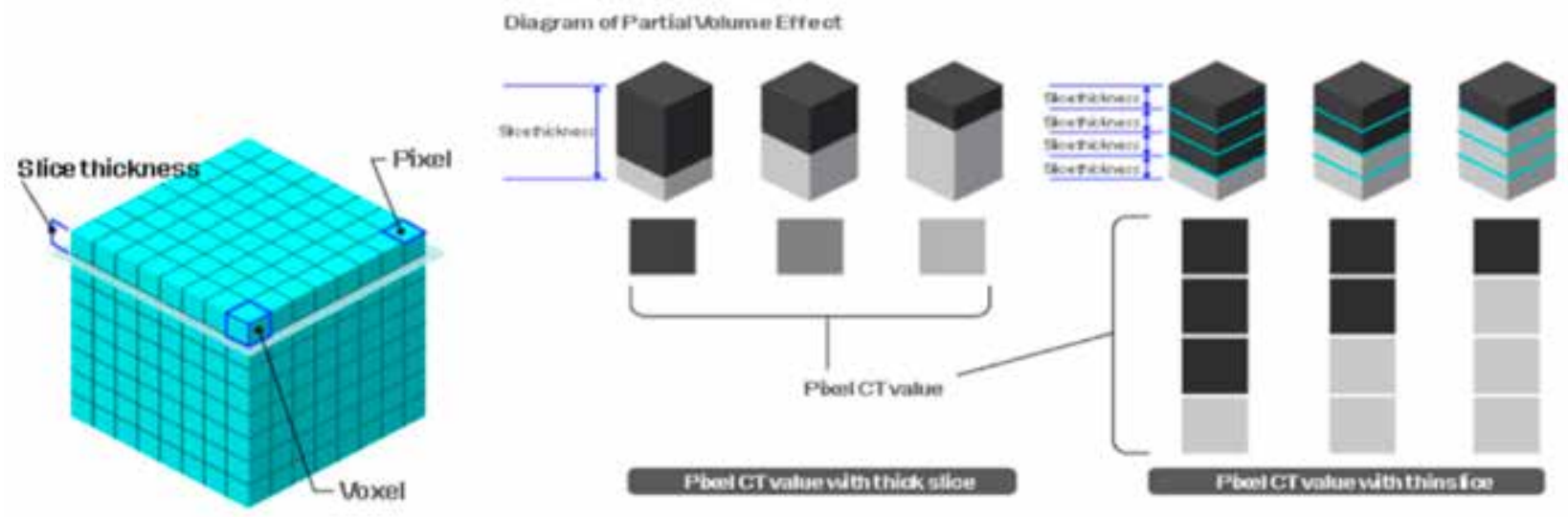

Şekil 1: BT'de parsiyel volüm etkisi. 
(50-100 mAs) ile \%93-97 doğru tanı oranına ulaşılırken radyasyon dozu \%80 azalır. Yüksek doğru tanı oranına rağmen yöntemin bir dezavantajı farklı vücut boyutları olanlar için sabit tüp akımının olmamasıdır. Her hasta için ayrı tarama değişkenleri kullanılmalıdır (6,7).

\section{Multidedektör BT (MDBT)}

Ürolitiasis tanısında \%95-98 sensitivite ve \%96-100 spesifisiteye sahip olup, tetkik saniyeler içerisinde tamamlan- maktadır. Tetkikte iv kontrast madde kullanılmaz. MDBT taş hastalığı yanı sıra şüphelenilmeyen üriner ve ekstraüriner anormallikleri de gösterir. Yöntem ayrıca apendisit, divertikülit, pankreatit ve jinekolojik lezyonları ortaya koyar. Multidedektör BT; tedavi planlaması, taş yükünün belirlenmesi, taş kompozisyonu ve taş frajilitesinin tespitinde önemli bilgiler sağlar $(2,8)$.

İzotropik volüm data elde edilmesini takiben; postprosessing algoritmler ve workstationlar kullanılarak taşın

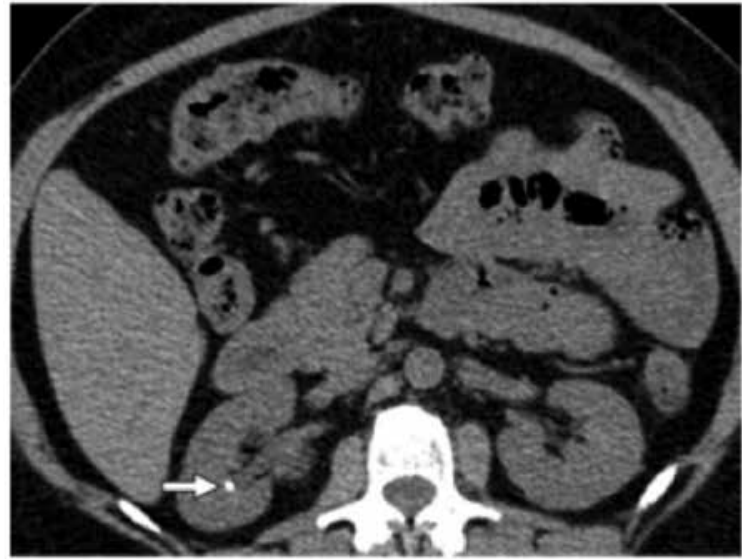

a.

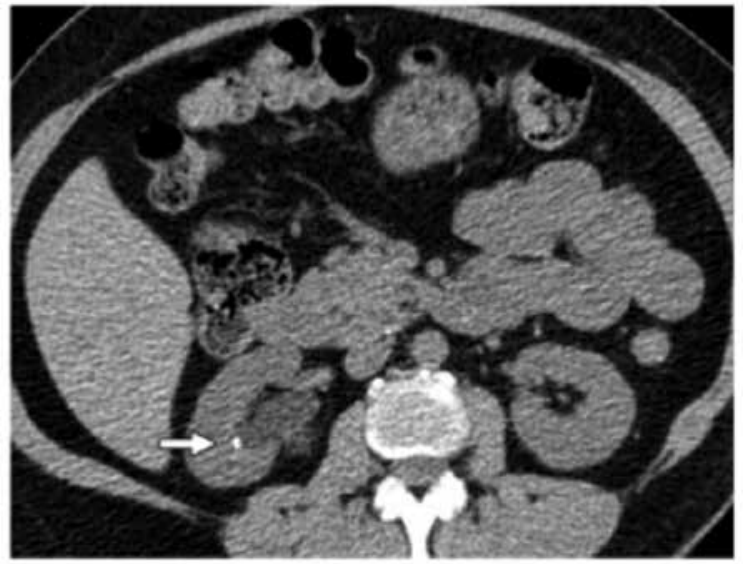

b.

Şekil 2: A.120 kVp, 240mAs B. 100 kVp, 100 mAs ile elde edilmiş BT kesitlerinde tanısal anlamda eksiklik olmayıp, hastanın aldığı radyasyon dozunda \%41 azalma sağlanmıştır.

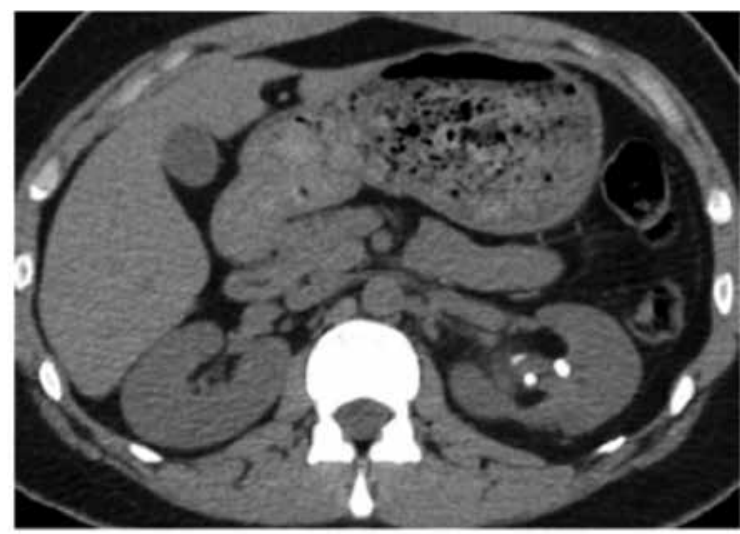

a.

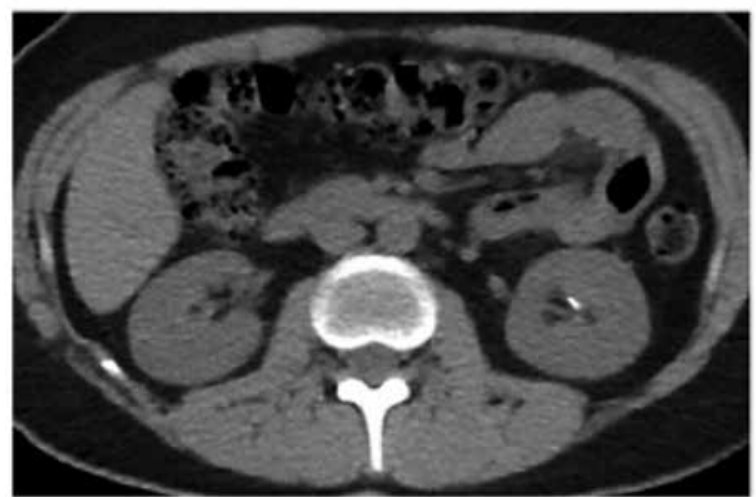

c.

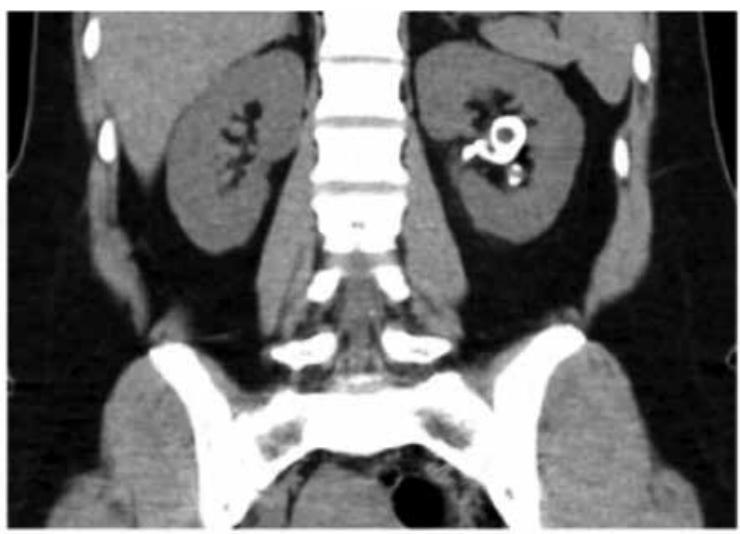

b.

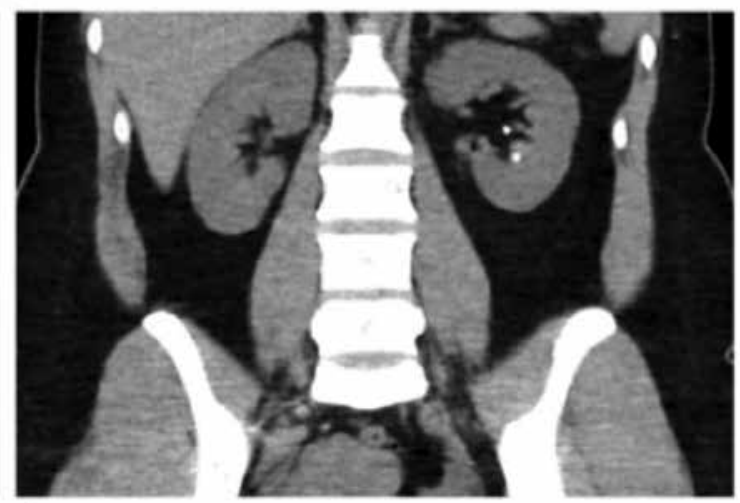

d.

Şekil 3: Koronal reformat görüntüler taş-stent ayrımında yararlıdır. 

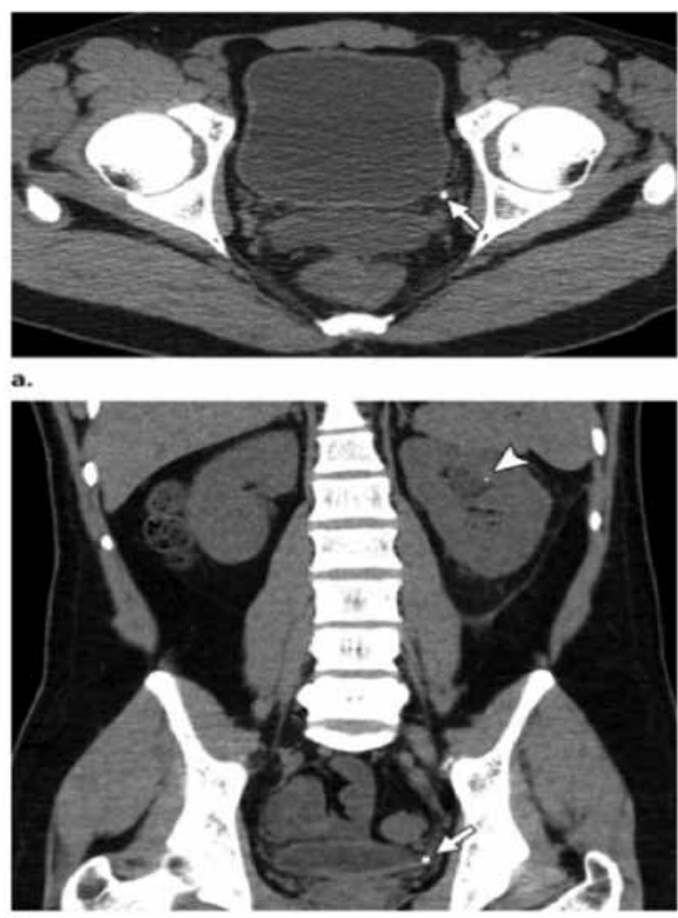

b.

Şekil 4: Reformat görüntüler atlanmış taşı gösterebilir. A. Sol üreter distalinde milimetrik boyutta taş dansitesi mevcut. Böbreklerde taş tesbit edilmemiş. B. Koronal reformat görüntülerde sol böbrekte üst pole yakın milimetrik taş görünümü mevcut.

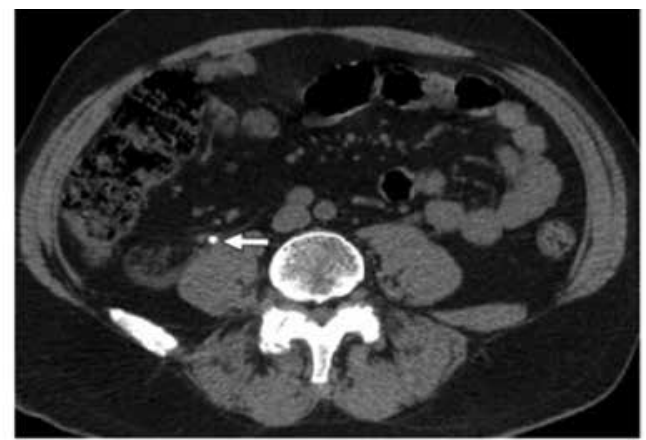

a.

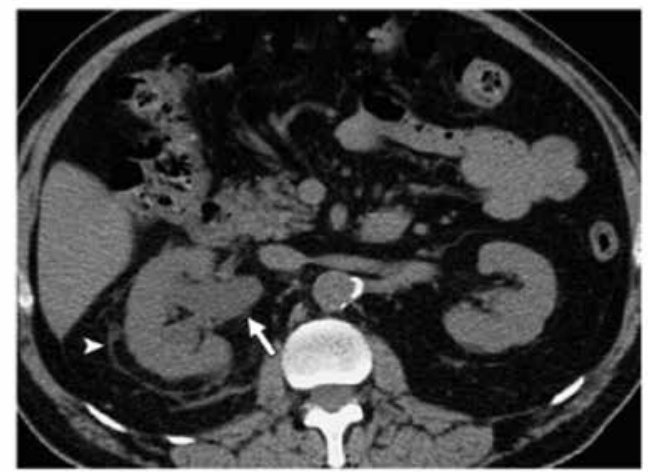

c. frajilitesi ve kompozisyonunu belirlemek için x ışını attenuasyon ölçümü ve taşın internal yapı karakterizasyonu yapılır. Kalsiyum ve ürik asit taş ayrımı Dual enerji BT ile oldukça kolaylaşmıştır (11).

MDBT tekniği: BT tekniğinde 3 mm'lik rekonstrüksiyonlar küçük taşları parsiyel volum etkisinden kurtarır. Beş mm kalınlık-3 mm reformat görüntülerin hastanın maruz kaldığı radyasyon dozunu azalttığı gösterilmiştir. Beş-10 mm kalınlıkta tarama ise küçük taşların atlanmasına neden olur. Taş görüntüleme ile radyasyon dozu dengesinin sağlanması önemlidir.

Tetkik sırasında rutinde iv kontrast kullanımı gerekmez ancak iv kontrast kullanımı distal üreter taşlarını flebolitten veya vasküler kalsifikasyonlardan ayırt etmede faydalıdır. Ayrıca insidental tümör tespitine, üreter striktürleri, UPJ obstrüksiyonu ve duplike sistemlerin görüntülenmesine yardımcı olur.

Rutin taş aramada aksiyel kesitler kullanılır. Software kullanılarak elde edilen koronal ve sagittal reformat görüntüler üreteri uzunlamasına göstererek taş impaksiyonunun kesin lokalizasyonunu tespit etmemize olanak sağlar. Üriner sistem koronal oriyente olduğu için koronal görüntüler taş aramada daha yararlıdır. Ayrıca reformat görüntüler taşları flebolit, kalsifiye vasküler plaklar, renal parenkimal kalsifikasyonlardan ayırt etmede aksiyel kesitlere yardımcıdır. Reformat görüntüler aksiyel kesitlerde atlanmış olan taşı gösterebilir (12-17)(Şekil 4).

MDBT bulguları: Düz grafide radyolüsen olan ürik asit, ksantin ve sistin taşları tespit edilebilir. Bu taşların dansiteleri genellikle 200 HU üzerindedir. Pür matriks taşları ve pür

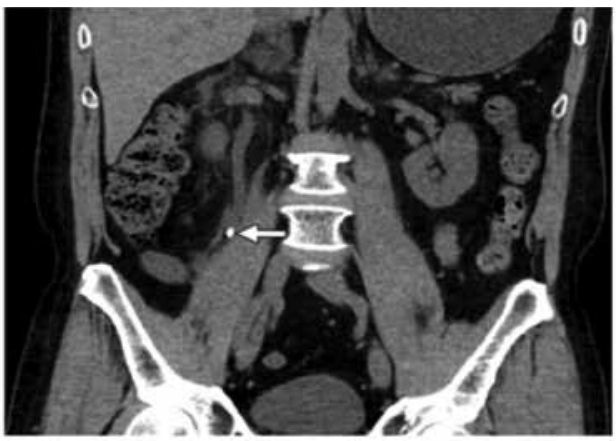

b.

Şekil 5: A. Sağ üreter proksimalinde taş izlenmektedir. B. Sağ üreterde hidroüreter görünümü. C. Perinefrik yağ dokusunda dansite artışı ve tek taraflı böbrek büyümesi 
indinavir taşları zor seçilir. Çünkü bu taşlar yumuşak doku dansitesindedir (15-30 HU). Bu taşlar intravenöz kontrast madde verildikten sonra geç faz görüntülerde dolma defekti şeklinde izlenir $(18,19)$. Taşın direkt BT bulgusu, üreter lümeninde taş ve taşın proksimalinde üreter dilatasyonudur. Üreter distalinde normal çap izlenir. Taşın sekonder bulguları ise "güvenilir bulgular" ve "daha az güvenilir bulgular" olarak 2 başlık altında incelenebilir. Taşın güvenilir bulguları, hidroüreter, hidronefroz, perinefrik yağ dokusunda dansite artışı, periüreteral ödem, tek taraflı böbrek büyümesi (Şekil 5) olarak sayılabilir. Taşın daha az güvenilir bulguları, tek taraflı beyaz renal piramid yokluğu, laterokonal fasya kalınlaşması, perinefrik ödem ve böbrek parenkim attenuasyon değerlerinde farklılık olarak verilebilir $(4,18)$.

\section{Üreter Taşlarını Diğer Kalsifikasyonlardan Ayırma}

Yumuşak doku halo belirtisi (rim sign): Kalsifikasyon çevresindeki yumuşak dokuda halo şeklinde attenuasyondur. Ödemli üreter duvarına işaret eder. Üreter taşı tesbitinde sensitivitesi \%57-70, spesifisitesi \%90-100'dür.

Kuyruklu yıldız belirtisi: Kalsifikasyon çevresinde ekzantrik, gittikçe incelen yumuşak doku alanı izlenir. Flebolit için güvenilir bir göstergedir. Flebolitte santral lusen alan gözlenirken, taşta santral opasifikasyon izlenir (Şekil 6). İşlem sonrası stent ve taş ayrımı için kemik pencerede inceleme gerekebilir (4).

Taş yükü tesbiti: Taş boyutları ölçülür. Staghorn taş gibi düzensiz konturlu olanlarda spiral BT ve düz grafide ölçüm zordur. Taş yükü ölçümü için çeşitli yöntemler önerilmiştir. Bunlar arasında taş çevresinin elektronik olarak işaretlenmesi, 3 boyutlu hacim ölçümü ve yeni yarı otomatik segmentasyon yöntemleri bulunur. Bir çalışmada $700 \mathrm{~mm}^{3}$ 'ün üzerınde hacme sahip taşların ESWL den fayda görmeyeceği gösterilmiştir $(20,21)$.

Taş dansitesi: Pek çok çalışmada taş BT attenuasyon değerinin SWL başarısında bir ön gösterge olduğu belirlenmiştir. Düşük taş attenuasyon değerlerinde SWL başarısı daha yüksek bulunmuştur. Bir çalışmada hastalar $780 \mathrm{HU}$ ve $0.4 \mathrm{~cm}^{2}$ kesit alanı cut off değeri kullanılarak 4 gruba ayrılmıştır. Bu değerler kullanılarak düşük HU değerine ve kesit alanına sahip taşı olan grubun SWL de başarılı sonuç alma olasılığı diğer gruplardan 11.6 kat fazla bulunmuştur (22).

Taş frajilitesi: Taş heterojenitesi taşın daha kolay fragmante olacağını düşündürür. BT'de heterojenite: internal düşük dansiteli alanlar olarak gözlenir (Şekil 7). Homojenite taş rijiditesinin yüksekliğini gösterebilir. İnternal morfolojik özelliklerin attenuasyondan önemli olduğunu iddia eden araştırmacılar mevcuttur (23).
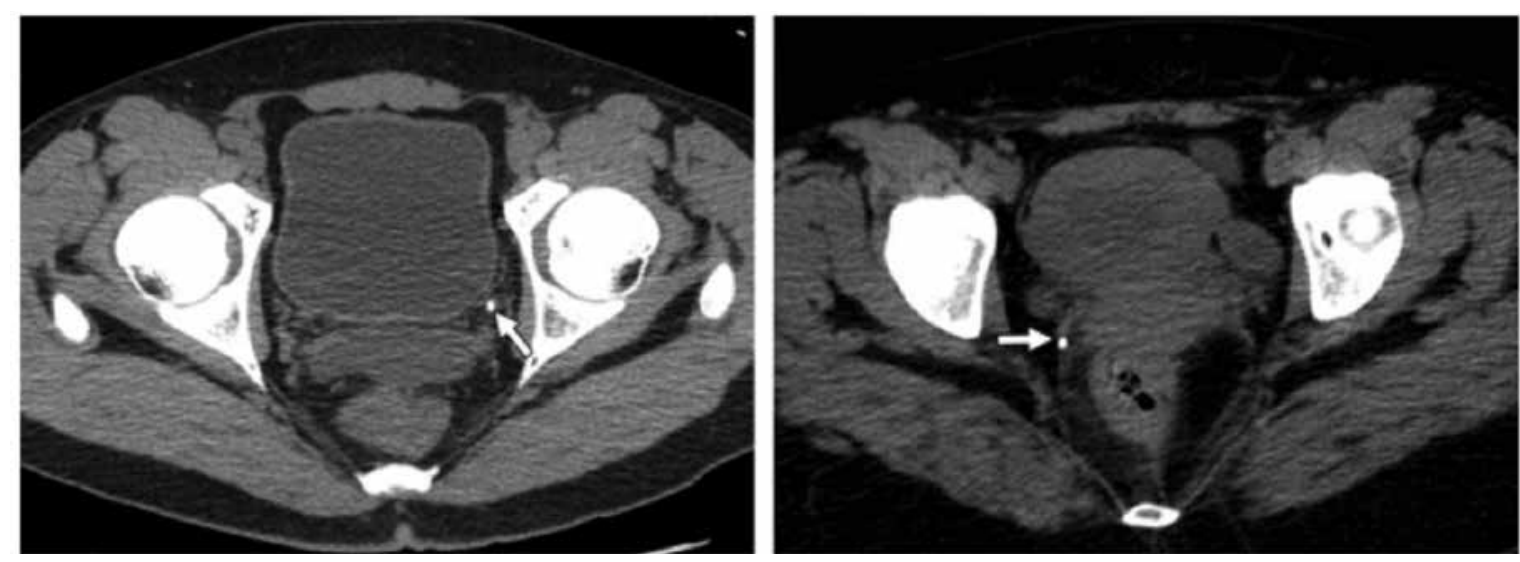

Şekil 6: Yumuşak doku halo-kuyruklu yıldız belirtisi

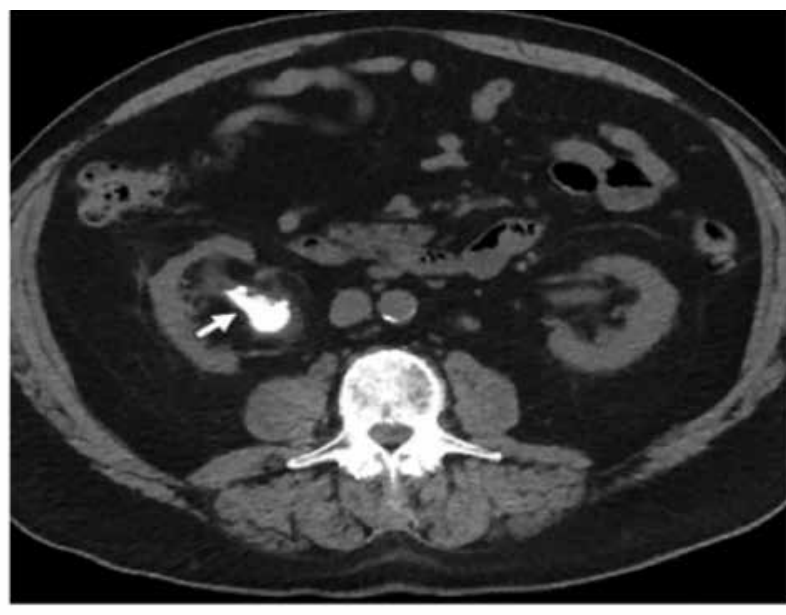

a.

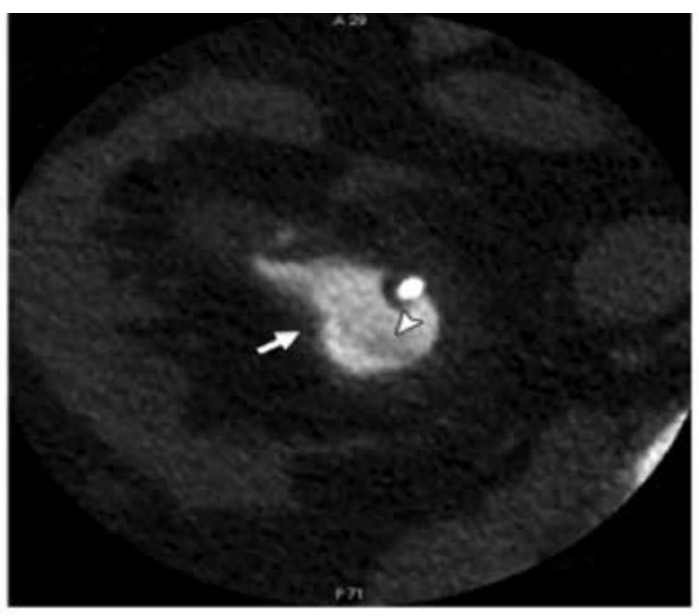

b.

Şekil 7: A. Abdominal pencerede incelenen sağ böbrekte taşın homojen iç yapıya sahip olduğu ancak b. kemik pencerede heterojen alanlar bulunduğu izlenmektedir. 

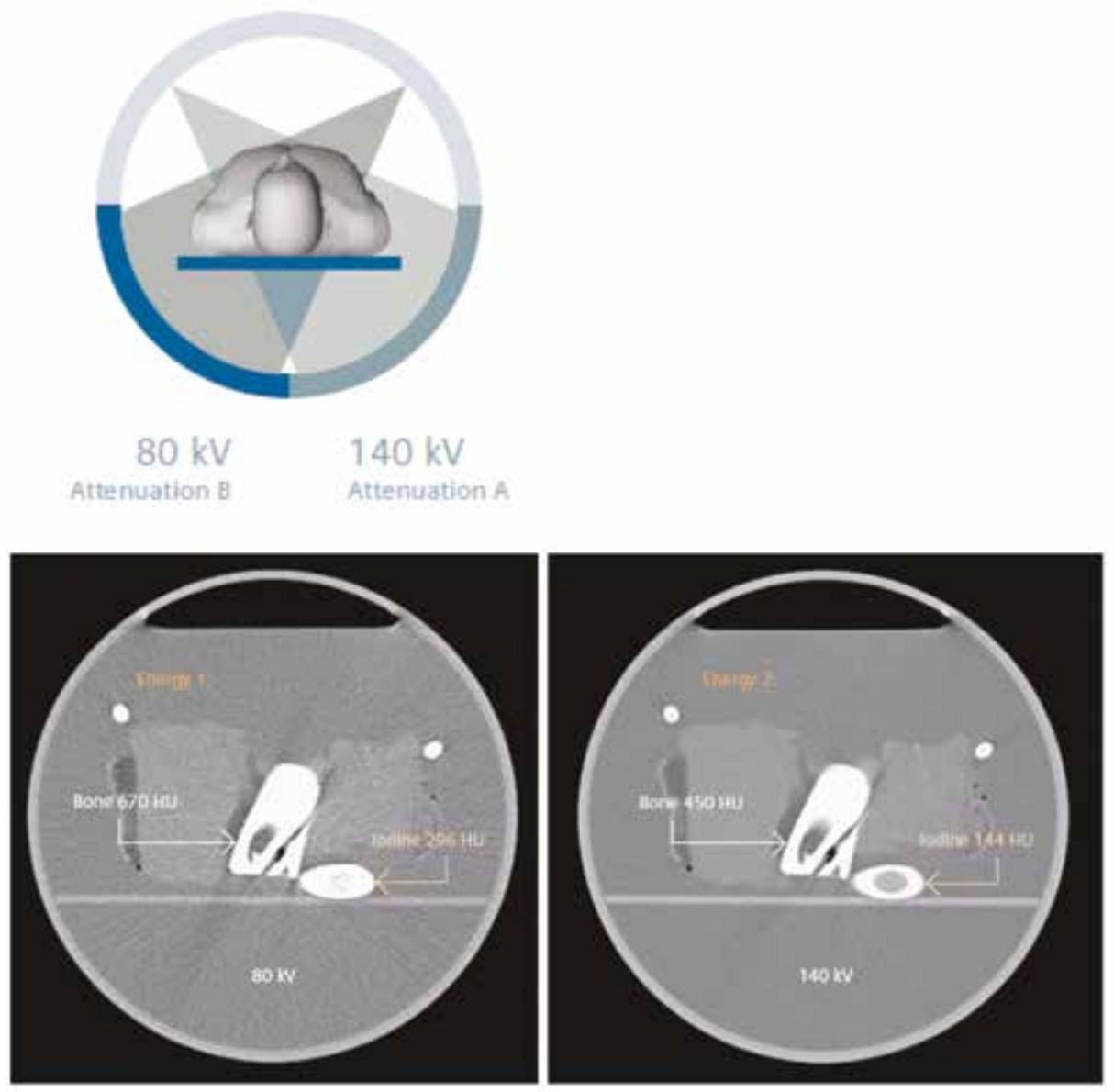

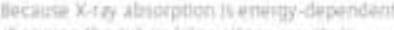

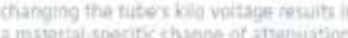

Şekil 8: A. Sağ üreter proksimalinde taş izlenmektedir. B. Sağ üreterde hidroüreter görünümü. C. Perinefrik yăg dokusunda dansite artışı ve tek taraflı böbrek büyümesi

\section{Dual enerji BT (DEBT)}

Dual enerji BT taş kompozisyonunu belirlemede gelecek vaat etmektedir. DEBT cihazı 90 derece açı ile monte edilmiş iki x ışın kaynağı ve 64'lük dedektörler içerir. İki farklı enerji ile tarama (80 ve $140 \mathrm{Kvp}$ ) yapılır $(24,25)$ (Şekil 8).

Tetkik doku materyal karakterizasyonunu sağlar. Ürik asit taşları hidrojen, oksijen, karbon, nitrojen gibi hafif elementlerden oluşurken kalsiyum oksalat, kalsiyum hidroksiapatit, sistin ve struvit taşları ise Fosfor, kalsiyum, sülfür gibi ağır elementlerden oluşur. Kimyasal kompozisyondaki bu farklılık düşük ve yüksek enerji x ışınlarında farklı attenuasyona neden olur. Taranan dokunun her vokselinde su, kalsiyum ve ürik asit ayrımı yapılır. Kalsiyum içeren vokseller mavi, ürik asit içerenler kırmızı ile kodlanır. Lineer attenuasyon gösteren vokseller gri kodlanır (Şekil 9). Pür ürik asit, mikst ürik asit ve kalsifiye taşlar ayırt edilir (26). Madde dekompozisyon algoritmi içeren yazılım kullanılarak struvit taşlarını sistin taşlarından ayırt etmek mümkün olabilir.

\section{Dual enerji BT uygulaması}

Taş kontrastsız düşük doz abdomen ve pelvis BT ile saptanır. Tespit edilen taşa yönelik dual enerji BT uygulanır.
Yüksek enerjili tarama-düşük enerjili taş odaklanması yapılarak hastanın alacağı radyasyon dozu azaltılır.

\section{Kaynaklar}

1. Sandhu C, Anson KM, Patel U. Urinary tract stones. I. Role of radiological imaging in diagnosis and treatment planning. Clin Radiol 2003;58(6): 415-421.

2. Avinash R. Kambadakone, MD, FRCR - Brian H. Eisner, MD - Onofrio Antonio Catalano, MD - Dushyant V. Sahani, MD. New and Evolving Concepts in the Imaging and Management of Urolithiasis: Urologists' Perspective. Radiographics 2010:30:603-623

3. Chen MY, Zagoria RJ, Saunders HS, Dyer RB. Trends in the use of unenhanced helical CT for acute urinary colic. AJR Am J Roentgenol 1999;173 (6):1447-1450.

4. Ege G, Akman H, Kuzucu K, Yildiz S. Acute ureterolithiasis: incidence of secondary signs on unenhanced helical CT and influence on patient management. Clin Radiol 2003;58(12):990-994.

5. Heneghan JP, McGuire KA, Leder RA, DeLong DM, Yoshizumi T, Nelson RC. Helical CT for neph-rolithiasis and ureterolithiasis: comparison of conventional and reduced radiation-dose techniques. Radiology 2003;229(2):575-580. 

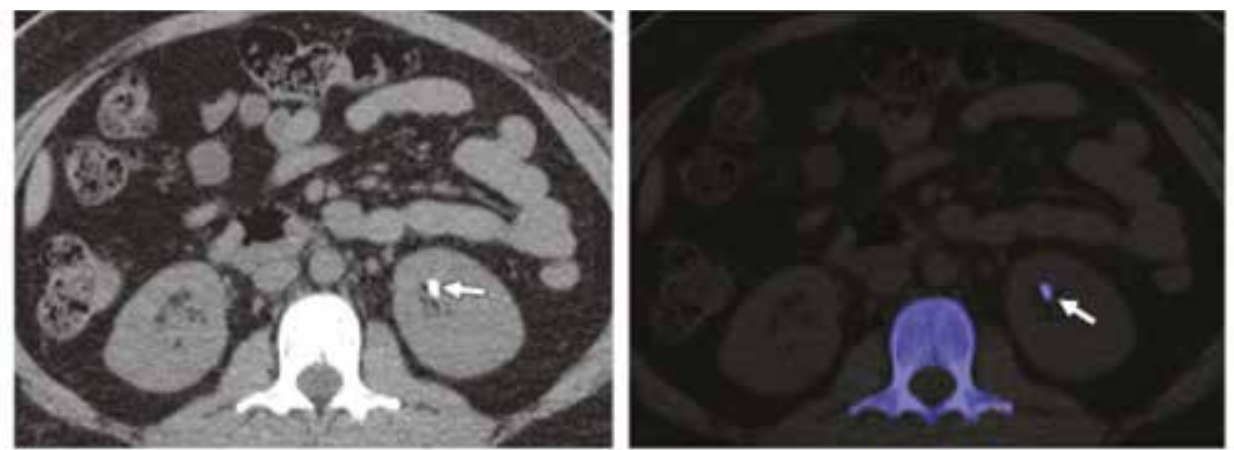

a.
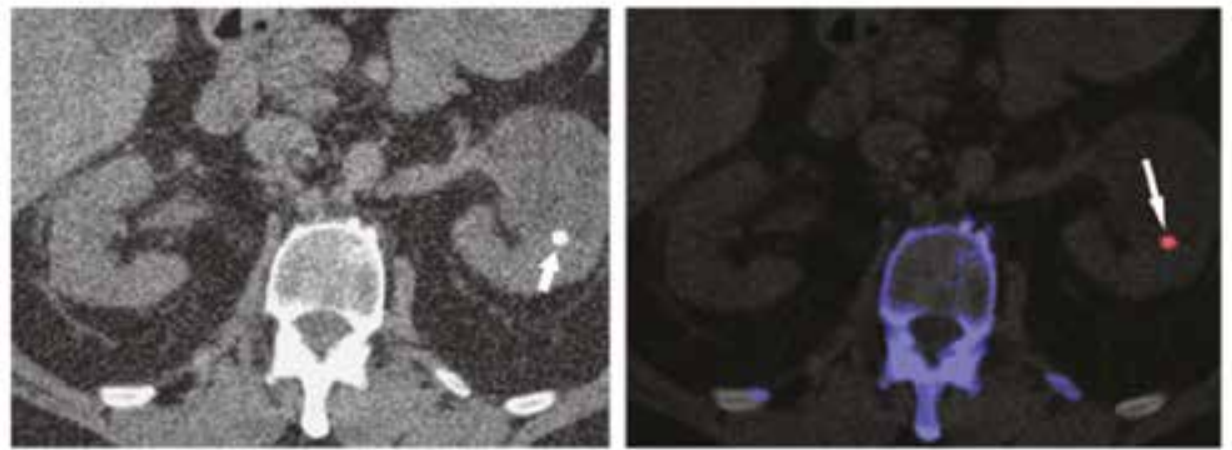

b.

Şekil 9: Kalsiyum içeren vokseller mavi, ürik asit içerenler kırmızı ile kodlanır. Lineer attenuasyon gösteren vokseller gri kodlanır. A. Sol böbrekte kalsiyum taşı B. Sol böbrekte ürik asit taşı izleniyor.

6. Lee $\mathrm{CH}$, Goo JM, Ye HJ, et al. Radiation dose modulation techniques in the multidetector CT era: from basics to practice. Radiographics 2008; 28(5):1451-1459.

7. Kim BS, Hwang IK, Choi YW, et al. Low-dose and standarddose unenhanced helical computed to-mography for the assessment of acute renal colic: prospective comparative study. Acta Radiol 2005; 46(7):756-763.

8. Boulay I, Holtz P, Foley WD, White B, Begun FP. Ureteral calculi: diagnostic efficacy of helical $\mathrm{CT}$ and implications for treatment of patients. AJR Am J Roentgenol 1999;172(6):1485-1490.

9. Lin WC, Uppot RN, Li CS, Hahn PF, Sahani DV. Value of automated coronal reformations from 64-section multidetector row computerized tomography in the diagnosis of urinary stone disease. J Urol 2007;178(3 pt 1):907-911

10. Metser U, Ghai S, Ong YY, Lockwood G, Radomski SB. Assessment of urinary tract calculi with 64- MDCT: the axial versus coronal plane. AJR Am J Roentgenol 2009;192(6):1509-1513.

11. Anno Graser Thorsten R. C. Johnson Hersh Chandarana Michael MacariDual energy CT: preliminary observations and potential clinical applications in the abdomen Eur Radiol (2009) 19: 13-23

12. Dalla Palma L, Pozzi-Mucelli R, Stacul F. Presentday imaging of patients with renal colic. Eur Radiol 2001;11(1):4-17.

13. Ketelslegers E, Van Beers BE. Urinary calculi: improved detection and characterization with thin-slice multidetector CT. Eur Radiol 2006;16(1): 161-165.
14. Memarsadeghi M, Heinz-Peer G, Helbich TH, et al. Unenhanced multidetector row CT in patients suspected of having urinary stone disease: effect of section width on diagnosis. Radiology 2005;235(2):530-536.

15. Park S, Pearle MS. Imaging for percutaneous renal access and management of renal calculi. Urol Clin North Am 2006;33(3):353-364.

16. Spencer BA, Wood BJ, Dretler SP. Helical CT and ureteral colic. Urol Clin North Am 2000;27(2): 231-241.

17. Eisner BH, Shaikh M, Uppot RN, Sahani DV, Dretler SP. Genitourinary imaging with noncontrast computerized tomography: are we missing duplex ureters? J Urol 2008;179(4):1445-1448.

18. Smith RC, Coll DM. Helical computed tomography in the diagnosis of ureteric colic. BJU Int 2000;86(suppl 1):33-41.

19. Bruce RG, Munch LC, Hoven AD, et al. Uroli-thiasis associated with the protease inhibitor indi-navir. Urology 1997;50(4):513-518.

20. Wang LJ, Wong YC, Chuang CK, et al. Predictions of outcomes of renal stones after extracorporeal shock wave lithotripsy from stone characteristics determined by unenhanced helical computed tomog raphy: a multivariate analysis. Eur Radiol 2005;15 (11):22382243.

21. Yoshida S, Hayashi T, Morozumi M, Osada H, Honda $\mathrm{N}$, Yamada T. Three-dimensional assessment of urinary stone on non-contrast helical computed tomography as the predictor of stonestreet formation after extracorporeal shock wave lithotripsy for stones smaller than $20 \mathrm{~mm}$. Int J Urol 2007;14(7): 665-667. 
22. M Tanaka, E Yokota, Y Toyonaga, et. al. Stone Attenuation Value and Cross-Sectional Area on Computed Tomography Predict the Success of Shock Wave Lithotripsy. Korean J Urol 2013;54:454-459

23. Zarse CA, Hameed TA, Jackson ME, et al. CT visible internal stone structure, but not Hounsfield unit value, of calcium oxalate monohydrate (COM) calculi predicts lithotripsy fragility in vitro. Urol Res 2007;35(4):201-206.

24. Flohr TG, McCollough $\mathrm{CH}$, Bruder $\mathrm{H}$, et al. First performance evaluation of a dual-source CT (DSCT) system. Eur Radiol 2006;16(2):256-268.

25. Johnson TR, Krauss B, Sedlmair M, et al. Material differentiation by dual energy CT: initial experience. Eur Radiol 2007;17(6):1510-1517.
26. Primak AN, Fletcher JG, Vrtiska TJ, et al. Noninvasive differentiation of uric acid versus nonuric acid kidney stones using dual-energy CT. Acad Radiol 2007;14(12):1441-1447.

Yazışma Adresi:

Tamer Baysal,

Kartal Dr. Lütfi Kırdar Eğitim ve Araştirma Hastanesi,

Radyoloji Kliniği, İstanbul

Tel: +90 5334249724

e-mail: tamerbaysal@hotmail.com 